\title{
Delayed puberty caused by hyperthyroidism in ram lambs is not a result of suppression in body growth
}

\author{
Y. Chandrasekhar, M. J. D'Occhio and B. P. Setchell
}

Department of Animal Sciences, Waite Agricultural Research Insitute, University of Adelaide, Glen Osmond, South Australia 5064, Australia

\begin{abstract}
Summary. Over a period of 8 weeks ram lambs (16 weeks old) were made hyperthyroidal (serum thyroxine $\cong 150 \mathrm{ng} / \mathrm{ml}$, compared with control $\cong 48 \mathrm{ng} / \mathrm{ml}$ ) by daily subcutaneous injections of thyroxine or maintained at a constant body weight by restriction of the feed intake. Hyperthyroidal and restricted-intake lambs remained at a constant body weight during the period of treatment whilst control rams gained body weight. Testicular growth was normal in restricted-intake lambs but was suppressed in hyperthyroidal animals. Hyperthyroidism, but not feed restriction, was also associated with decrease in $\mathrm{LH}$ pulse frequency $(1 \cdot 3 \pm 0 \cdot 3 / 12 \mathrm{~h}$ compared with controls $4 \cdot 8 \pm 0 \cdot 9 / 12 \mathrm{~h}$. Hyperthyroidal lambs showed normal $\mathrm{LH}$ responses to exogenous LHRH. After cessation of treatment testicular growth continued to be suppressed for up to 16 weeks in previously hyperthyroidic rams; thereafter testes began to increase in size but at 30 weeks after treatment were still smaller than those of control rams. It is concluded that elevated thyroxine concentrations directly influence sexual maturation in ram lambs through actions at hypothalamic and/or higher brain centres which control LH secretion. Transient hyperthyroidism during sexual maturation may cause permanent impairment of sexual development.
\end{abstract}

\section{Introduction}

Induced hyperthyroidism of ram lambs suppressed body growth and was also associated with retarded testicular development and arrested spermatogenesis (Chandrasekhar, D'Occhio, Holland \& Setchell, 1985). Changes in reproductive endocrine function in these animals included decreased pulsatile release of $\mathrm{LH}$, an observation that led to the suggestion that hyperthyroidal ram lambs do not experience the increase in LH pulse frequency considered to be the main endocrine signal for initiation of pubertal maturation of the immature testis (Foster et al., 1978; Echternkamp \& Lunstra, 1984).

Another explanation for retarded testicular growth in hyperthyroidal lambs could be provided by the critical body mass hypothesis (Frisch \& Revelle, 1970, 1971; Frisch, 1972) which states that puberty is triggered when animals reach a certain body weight. However, the validity of the critical weight concept has been questioned (Glass, Harrison \& Swerdloff, 1976; Glass \& Swerdloff, 1980; Glass, Anderson, Herbert \& Vigersky, 1984; Kulin, Bwibo, Mutie \& Sautner, 1982) and the exact nature of the relationship between body growth and sexual maturation remains unclear. The present study examined further the basis for retarded testicular development in hyperthyroidic ram lambs by comparing sexual maturation in such rams with that of ram lambs maintained at a constant body weight by restricting dietary feed intake. 


\section{Materials and Methods}

Twelve Merino ram lambs ( 16 weeks old at the start of the experiment, $22 \cdot 0 \pm 1 \cdot 1 \mathrm{~kg}$ bodyweight) were housed indoors from October to December (spring) in individual pens under natural lighting. Animals were randomly allocated to three equal groups. One group contained control rams fed ad libitum (Group C), feed intake in Group FR was adjusted to maintain bodyweight at a constant level, and rams in Group HT were fed ad libitum but made hyperthyroidal by daily subcutaneous injection of thyroxine $(25 \mu \mathrm{g} / \mathrm{kg}$ bodyweight) in alkaline saline (Chandrasekhar et al., 1985). Lambs in Groups $\mathrm{C}$ and FR received daily injections of alkaline saline. During an acclimatization period all lambs received daily $300 \mathrm{~g}$ lucerne (alfalfa) chaff and $800 \mathrm{~g}$ commercial sheep pellets. Without changing the composition of the diet the amount of food was adjusted at the beginning of the experimental period and by Week 2 animals in Group FR were receiving $\sim 50 \%$ less food while those in Group HT were consuming $\sim 50 \%$ more food than those in Group C. Treatments were continued for 8 weeks and at the end of the treatment period animals were returned to pasture and periodic measurements of bodyweight and testis size were made up to 54 weeks of age. Under similar conditions ram lambs of this breed reach maturity between 20 and 24 weeks (Chandrasekhar et al., 1985).

Weekly measurements. Weekly measurements included body weight and testicular volume; blood samples (three at 20 -min intervals) were taken by jugular venepuncture. The volume of one testis was estimated from calliper measurements of its diameters, by assuming that it was a prolate spheroid according to the formula $1 / 6 . \pi, a^{2} . b$ ( $a=$ diameter at largest circumference, $b=$ length of the testis).

During Week 7 of treatment, indwelling cannulae (polyethylene tubing; i.d. $1 \mathrm{~mm}$, o.d. $1.5 \mathrm{~mm}$; Dural Plastics \& Engineering, Dural, NSW, Australia) were placed in a jugular vein of all animals. Cannulae were used for taking blood samples and for injecting LH-releasing hormone (LHRH). Beginning at 04:00 h the following day, blood samples were taken at 20 -min intervals for $12 \mathrm{~h}$. At 16:00 h animals received a bolus intravenous injection of LHRH $(5 \mathrm{ng} / \mathrm{kg}$ bodyweight; Sigma, St Louis, MO, U.S.A.) and additional blood samples were taken at 10, 20, 30, 40, 60 and 120 min after LHRH injection (Chandrasekhar et al., 1985). Peak LH and testosterone responses after LHRH were calculated as the highest concentration reached, minus the respective hormone concentration at the time of LHRH injection.

Hormone assays. Double-antibody radioimmunoassay procedures were used to measure serum LH, FSH and prolactin concentrations. Reference standards were NIADDH-oLH-24 for LH, NIADDK-oFSH-15 for FSH, and NIADDK-oPRL-16 for prolactin. Testosterone concentrations were determined by an extraction radioimmunoassay for which the specificity and extraction efficiency have been determined (D’Occhio \& Brooks, 1983). A direct radioimmunoassay was used to measure serum thyroxine (Burke $\&$ Shakespear, 1976). Standards and samples (when necessary) were diluted in phosphate buffer and the sensitivities (twice standard deviation of a buffer blank) of these assays per tube were $31 \mathrm{pg}$ (thyroxine), $5 \mathrm{pg}$ (testosterone), $0.5 \mathrm{ng}$ (FSH), $8 \mathrm{pg}$ (LH) and $0 \cdot 25 \mathrm{ng}$ (prolactin) using up to $10,100,200,400$ and $50 \mu \mathrm{l}$ serum, respectively. Intra- and inter-assay coefficients of variation $(100 \times$ standard deviation/mean) were $<10 \%$ when calculated from the replicates of a sample run in the same assay and three samples of different concentration (low, medium and high) run in duplicate in each assay, respectively.

LH pulse analysis. Basal LH concentrations were computed from values not associated with the ascending or descending portions of $\mathrm{LH}$ peaks. Mean $\mathrm{LH}$ concentrations represent the average of all 20-min samples collected during a 12-h period. The criteria used to distinguish increases in serum LH concentrations as LH pulses were that (1) the rise in LH was preceded by at least two successive $\mathrm{LH}$ values that showed a progressive decline or were at basal levels, and (2) the increase 

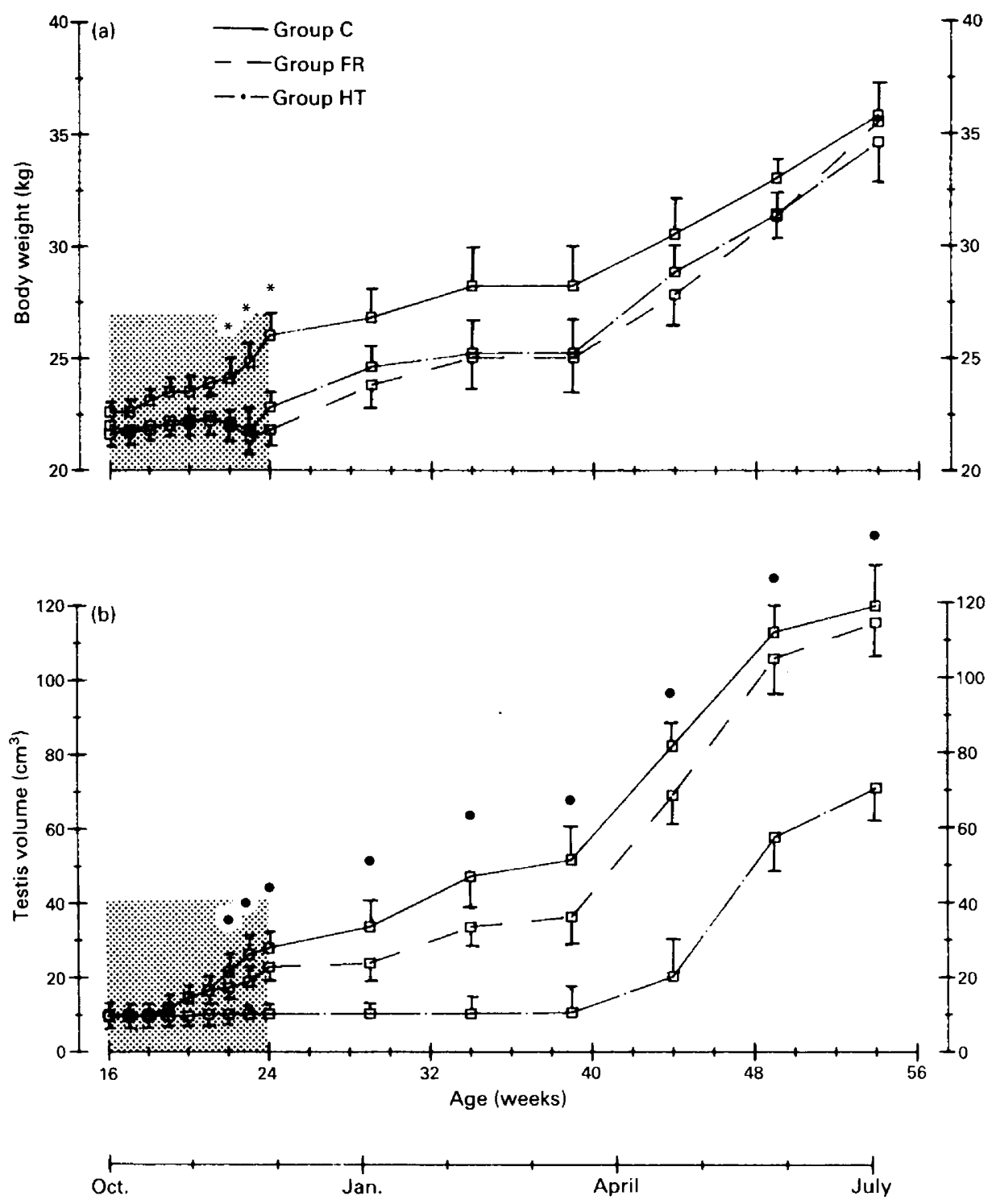

Fig. 1. Changes (mean \pm s.e.m.) in (a) the bodyweight and (b) testicular volume in 4 ram lambs in Group C (control), Group FR (restricted feed intake) and Group HT (hyperthyroidal) from 16 to 54 weeks of age. Treatments were imposed for 8 weeks between 16 and 24 weeks (shaded area) and then animals were returned to pastures. ${ }^{*}$ Values for lambs in Groups FR and HT significantly $(P<0.05)$ different from those in Group C. Values significantly $(P<0.05)$ different from those in Groups $C$ and FR.

in LH was greater than the within-assay variation (Chandrasekhar et al., 1985). LH peak amplitude was defined as the highest point associated with an LH peak minus the basal LH concentration.

Statistical analysis. Significance of difference was assessed by analysis of variance with appropriate transformation of the data when necessary. Comparisons between treatment means were by Duncan's new multiple range test. 


\section{Results}

Hyperthyroidism was effectively induced by exogenous thyroxine. From the first week of treatment ram lambs in Group HT maintained significantly $(P<0.001)$ higher levels of serum thyroxine $(152 \pm 7 \mathrm{ng} / \mathrm{ml})$ compared with those in Group C $(48 \pm 3 \mathrm{ng} / \mathrm{ml})$ and Group FR $(48 \pm 2 \mathrm{ng} / \mathrm{ml})$ which maintained steady levels and did not differ from each other.

\section{Bodyweight}

Body weights were similar for the three groups at the start of treatment $(22.0 \pm 1 \cdot 1 \mathrm{~kg})$. During treatment lambs in Group C gained in bodyweight (3.50 $\pm 0.91 \mathrm{~kg})$ while those in Groups FR and HT maintained constant body weight (Fig. la). After treatment animals in Groups FR and HT showed compensatory gains in bodyweight and by 54 weeks of age, both groups were similar to controls (Fig. 1a).

\section{Testicular size}

Testicular volume was similar for animals in the three groups at the beginning of treatment $\left(9.7 \pm 1.2 \mathrm{~cm}^{3}\right)$. Volume of one testis at the end of treatment in Group HT lambs $\left(10 \cdot 2 \pm 2.2 \mathrm{~cm}^{3}\right)$ was significantly $(P<0.05)$ lower than that in lambs in Group C $\left(27.8 \pm 4.4 \mathrm{~cm}^{3}\right)$ and Group FR $\left(22.7 \pm 5.6 \mathrm{~cm}^{3}\right)$ which did not differ from one another (Fig. $\mathrm{lb}$ ). The difference between the testes of animals in Groups HT and C became apparent from Week 20 onwards; the growth of the testes of Group FR rams appeared to fall slightly behind that of Group C lambs from Week 22 onwards, but this difference was significant only for Week 23 and they were still significantly larger than the testes of lambs in Group HT. Even at 30 weeks after the end of treatment, testicular growth continued to be reduced in lambs in Group HT. The volume of a single testis at 54 weeks of age in Group HT lambs $\left(75 \pm 8 \mathrm{~cm}^{3}\right)$ was significantly $(P<0.05)$ lower than that of Group $C$ $\left(119 \pm 18 \mathrm{~cm}^{3}\right)$ and Group FR $\left(114 \pm 17 \mathrm{~cm}^{3}\right)$ animals; this difference was significant at all times from the end of the treatment period. The small difference between the testes of animals in Groups $\mathrm{C}$ and $\mathrm{FR}$ was not significant in the period after treatment.

Table 1. Changes in plasma testosterone and $\mathrm{LH}$ concentrations in ram lambs in Group C (control), Group FR (restricted feed intake) and Group HT (hyperthyroidal)

\begin{tabular}{|c|c|c|c|c|c|c|}
\hline \multirow{2}{*}{$\begin{array}{l}\text { Week of } \\
\text { treatment }\end{array}$} & \multicolumn{3}{|c|}{ Testosterone $(\mathrm{ng} / \mathrm{ml})$} & \multicolumn{3}{|c|}{ LH (ng/ml) } \\
\hline & Group C & Group FR & Group HT & Group C & Group FR & Group HT \\
\hline 0 & $0.75 \pm 0.40$ & $0.45 \pm 0.18$ & $0.27 \pm 0.08$ & $0.21 \pm 0.02$ & $0.14 \pm 0.03$ & $0 \cdot 30 \pm 0 \cdot 11$ \\
\hline 1 & $1 \cdot 10 \pm 0.42$ & $1 \cdot 12 \pm 0.17$ & $0.80 \pm 0.18$ & $0.38 \pm 0.09$ & $0.16 \pm 0.02$ & $0 \cdot 16 \pm 0.02$ \\
\hline 2 & $0.95 \pm 0.25$ & $0.70 \pm 0.15$ & $0 \cdot 19 \pm 0 \cdot 12$ & $0.35 \pm 0.09$ & $0 \cdot 42 \pm 0 \cdot 14$ & $0 \cdot 14 \pm 0.04$ \\
\hline 3 & $0.96 \pm 0.35$ & $1 \cdot 16 \pm 0.34$ & $0.98 \pm 0.32$ & $0.42 \pm 0.17$ & $0 \cdot 29 \pm 0 \cdot 10$ & $0.14 \pm 0.01$ \\
\hline 4 & $0.63 \pm 0.13$ & $0.76 \pm 0.23$ & $0.09 \pm 0.01$ & $0.50 \pm 0.13$ & $0.21 \pm 0.08$ & $0.13 \pm 0.01)$ \\
\hline 5 & $1.03 \pm 0.17$ & $0.77 \pm 0.14$ & $0.21 \pm 0.07$ & $0.52 \pm 0.20$ & $0.23 \pm 0.03$ & $0 \cdot 19 \pm 0 \cdot 10$ \\
\hline 6 & $1.51 \pm 0.43\}$ & $1 \cdot 13 \pm 0.31\} a$ & $0.54 \pm 0.22\}$ & $0.29 \pm 0.05$ & $0.21 \pm 0.06\}$ & $0.11 \pm 0.02\}$ \\
\hline 7 & $0.98 \pm 0.09$ & $0.95 \pm 0.06$ & $0.34 \pm 0.13$ & $0.64 \pm 0.40$ & $0.20 \pm 0.04$ & $0 \cdot 10 \pm 0.01$ \\
\hline 8 & $1.21 \pm 0.26$ & $0.95 \pm 0.35$ & $0.46 \pm 0.38$ & $0.37 \pm 0.11$ & $0.26 \pm 0.06)$ & $0.11 \pm 0.03$ \\
\hline
\end{tabular}

Values are mean \pm s.e.m. for 4 animals/group. Analysis of variance of data after logarithmic (testosterone) or reciprocal $(\mathrm{LH})$ transformation for Weeks 48 after start of treatment: columns within a parameter without a common superscript differ significantly (testosterone: $P<0 \cdot 05$ ) or approaching significance (LH: $P<0 \cdot 10$ ). 
Longitudinal changes in plasma testosterone, LH, FSH and prolactin concentrations

From Week 4 to 8 of treatment, lambs in Group HT had significantly $(P<0.01)$ lower serum testosterone levels compared with those in Groups C and FR, which did not differ (Table 1). Plasma LH concentrations in Group HT animals were also slightly $(P<0 \cdot 1)$ lower than those in Groups $\mathrm{C}$ and FR which did not differ from each other (Table 1). There were no differences in FSH and prolactin concentrations between the groups (overall mean \pm s.e.m. $6 \cdot 1 \pm 0.1 \mathrm{ngFSH} / \mathrm{ml}$ and $397 \pm 11 \mathrm{ng}$ prolactin $/ \mathrm{ml})$.
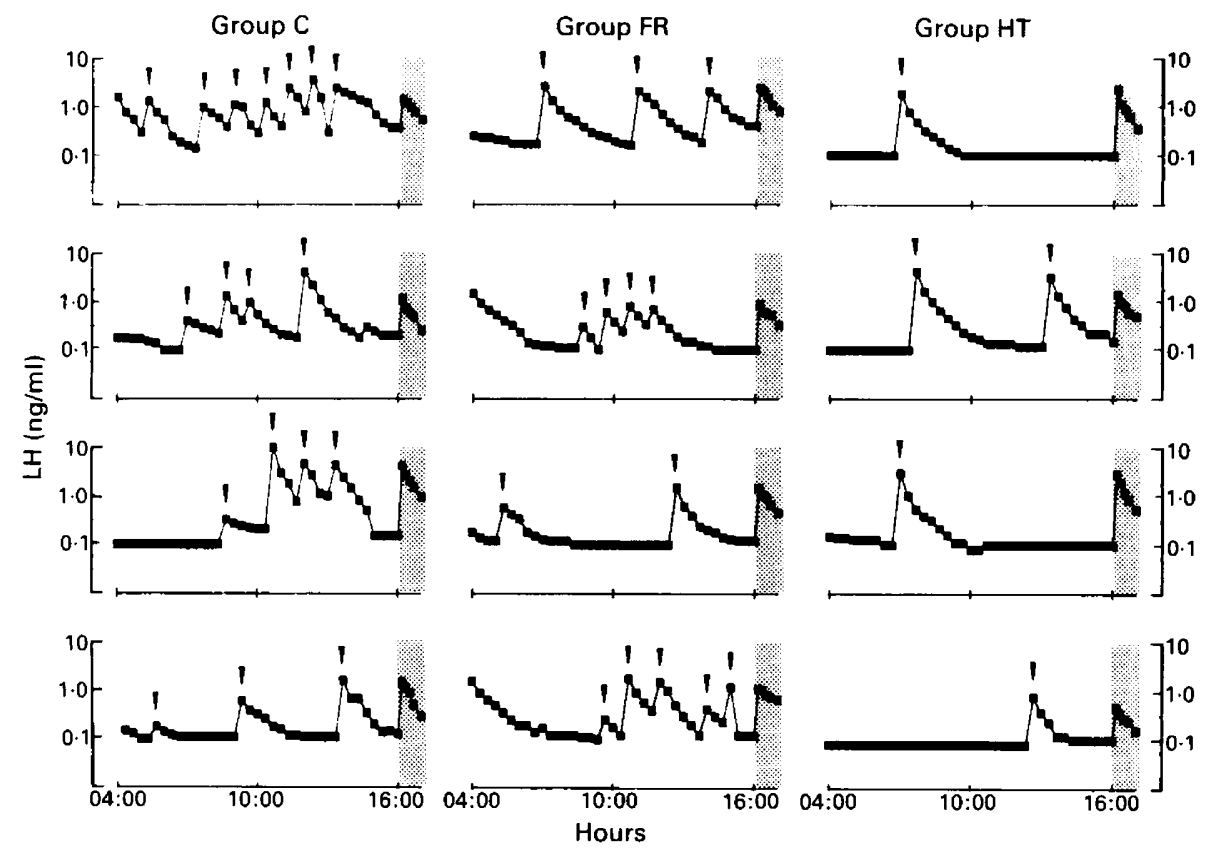

Fig. 2. Serum LH profiles in ram lambs in Group C (control), Group FR (restricted feed intake) and Group HT (hyperthyroidal), bled at 20-min intervals for $12 \mathrm{~h}$ during Week 7 of treatment (23 weeks of age). LH concentrations are plotted on a log scale. $\nabla$ indicates the peaks that are classified as pulses. Shaded area represents the $\mathrm{LH}$ secretory response after a bolus intravenous injection of LHRH at 16:00 $\mathrm{h}$.

\section{Serum LH profiles}

Lambs in Group C showed frequent LH pulses $(4 \cdot 8 \pm 0.9 / 12 \mathrm{~h}$; range $3-7)$ which had an amplitude of $2.1 \pm 0.5 \mathrm{ng} / \mathrm{ml}$ (Fig. 2). The basal concentration of $\mathrm{LH}$ in these lambs was $0.16 \pm 0.03 \mathrm{ng} / \mathrm{ml}$ during the $12-\mathrm{h}$ period with a mean concentration of $0.72 \pm 0.20 \mathrm{ng} / \mathrm{ml}$. Lambs in Group FR had basal LH concentrations of $0.15 \pm 0.02 \mathrm{ng} / \mathrm{ml}$ and showed pulses of comparable frequency and amplitude to those in Group C; LH pulses ranged from 2 to 4 with a mean value of $3.3 \pm 0.5 / 12 \mathrm{~h}$, the mean amplitude was $1.07 \pm 0.35 \mathrm{ng} / \mathrm{ml}$ and mean LH levels were $0.39 \pm 0.10 \mathrm{ng} / \mathrm{ml}$ (Fig. 2). In Group HT lambs the number of $\mathrm{LH}$ pulses $(1 \cdot 3 \pm 0 \cdot 3 / 12 \mathrm{~h}$ ) and mean LH concentrations $(0.25 \pm 0.08 \mathrm{ng} / \mathrm{ml})$ were significantly $(P<0.05)$ lower than in animals in Groups C and FR, although the amplitude of the pulses $(2.2 \pm 0.6 \mathrm{ng} / \mathrm{ml})$ and basal $\mathrm{LH}$ concentrations $(0 \cdot 10 \pm 0 \cdot 01 \mathrm{ng} / \mathrm{ml})$ were not different (Fig. 2). 


\section{Responses to $\mathrm{LHRH}$}

Injections of LHRH given during Week 7 of treatment were effective in inducing a release of LH with maximal increases generally observed 10 min after LHRH injection (Fig. 2). Lambs in Group HT showed increases in $\mathrm{LH}$ values that were not different from those of animals in Groups $\mathrm{C}$ and FR $(1.66 \pm 0.53,1.85 \pm 0.74$, and $1.21 \pm 0.31 \mathrm{ng} / \mathrm{ml}$, respectively). However, the testosterone increase was significantly $(P<0.05)$ lower in Group HT lambs $(0.20 \pm 0.04 \mathrm{ng} / \mathrm{ml})$ than in Group $\mathrm{C}(1.52 \pm 0.42 \mathrm{ng} / \mathrm{ml})$ and Group FR $(1.59 \pm 0.43)$ animals, which did not differ.

\section{Discussion}

The present study aimed to determine whether suppressed sexual maturation in hyperthyroidal ram lambs represents a direct response to hyperthyroidism or whether it is related more generally to an overall suppression in body growth. In these experiments, hyperthyroidal ram lambs remained at a constant body weight during the period of treatment and showed retarded testicular growth, confirming previous observations (Chandrasekhar et al., 1985). In contrast, the testes of ram lambs maintained at a constant body weight by dietary restriction underwent normal development. It can be concluded, therefore, that hyperthyroidism directly influences sexual maturation in the ram. Elevated thyroxine concentrations could interfere with pubertal development through mechanisms which alter gonadotrophin secretion or by direct actions at the gonads. A characteristic feature of the LH profiles of hyperthyroidal rams was a decreased incidence of LH pulses, but mean LH values were also lowered in hyperthyroidal rams. The latter observations were consistent with previous findings and provided further evidence that hyperthyroidism interferes with sexual maturation in ram lambs by altering patterns of gonadotrophin secretion (Chandrasekhar et al., 1985), especially as ram lambs receiving restricted dietary intake showed normal patterns of gonadotrophin secretion and normal testicular growth. In ram lambs, and also males of other species, pulsatile LH secretion is considered necessary for pubertal development of the testes (Foster et al., 1978; Schanbacher, D'Occhio \& Kinder, 1982; Echternkamp \& Lunstra, 1984).

The continued suppression in testicular growth in the hyperthyroidal lambs after treatment has ceased suggests that hyperthyroidism during a critical period of sexual maturation could permanently impair testicular development in the ram and it will be important to see whether this applies to other species.

Normal testicular development observed in ram lambs maintained at a constant body weight by restricted dietary intake was consistent with results of a study in which LH pulse frequency and testicular growth were not altered in ram lambs receiving low energy diets (Fitzgerald, 1984). In ewe lambs, however, undernutrition impaired gonadotrophin secretion and delayed puberty (Foster \& Olster, 1985). Similarly, in wild house mice, food restriction prevents reproductive development in females but not males (Hamilton \& Bronson, 1985). In man, malnourished boys are lighter than normal youths of the same pubertal stage (Kulin et al., 1982). Collectively these studies suggest that there exists a sexual dimorphism in mammals in the effects of nutrition on pubertal maturation. Sheep provide a further example of sexual dimorphism in the sensitivity of the pubertal process since photoperiod apparently influences sexual maturation in ewe lambs but not ram lambs (Claypool, 1985). Puberty in the female may therefore generally be more sensitive to enteroceptive and exteroceptive stimuli compared with the male. This concept is consistent with the idea that increases in body size and sexual maturation in males are processes that separately reflect the underlying development of an individual without having a direct link (Glass et al., 1984).

In summary the present data indicate that hyperthyroidism directly suppresses sexual maturation in ram lambs through actions of thyroxine at hypothalamic and/or higher brain centres. Transient hyperthyroidism during important phases of sexual maturation may, in some species, cause permanent impairment of sexual development. 
We thank Dr D. J. Bolt (USDA, Beltsville, Maryland, U.S.A.), Dr W. R. Butt (Birmingham and Midland Hospital for Women, Birmingham, U.K.), Dr R. I. Cox (CSIRO, Blacktown, NSW, Australia), Dr D. R. Lindsay (University of Western Australia, Nedlands, Western Australia), Dr C. W. Burke (Radcliffe Infirmary, Oxford, U.K.), Dr L. E. Reichert, Jr (Albany Medical College, NY, U.S.A.) and the NIADDK (Bethesda, U.S.A.) for generous supplies of radioimmunoassay materials; Mr S. Sowerbutts for expert technical assistance; Miss M. Morris for statistical analysis; and Mrs S. Suter for typing the manuscript.

\section{References}

Burke, C.W. \& Shakespear, R.A. (1976) Triiodothyronine and thyroxine in urine II. Renal handling and effects of urinary protein. $J$. clin. Endocr. Metab. 42 , 504-513.

Chandrasekhar, Y., D'Occhio, M.J., Holland, M.K. \& Setchell, B.P. (1985) Activity of the hypothalamopituitary gonadal axis and testicular development in prepubertal ram lambs with induced hypothyroidism or hyperthyroidism. Endocrinology 117, 1645-1651.

Claypool, L.E. (1985) Sexual maturation of sheep: photoperiod that delays puberty in the female does not retard prepubertal testicular growth. Biol. Reprod. 32 (Suppl. 1), 176, Abstr. 278.

D'Occhio, M.J. \& Brooks, D.E. (1983) Seasonal changes in plasma testosterone concentrations and mating activity in Border Leicester, Poll Dorset, Romney and Suffolk rams. Aust. J. exp. Agric. Anim. Husb. 23, 248-253.

Echternkamp, S.E. \& Lunstra, D.D. (1984) Relationship between LH and testicular development in progesterone-implanted prepubertal ram lambs. J. Anim. Sci. 59, 441-453.

Fitzgerald, J.A. (1984) The effect of castration, estradiol and LHRH on LH secretion of lambs fed different levels of dietary energy. J. Anim. Sci. 59, 460-475.

Foster, D.L. \& Olster, D.H. (1985) Effect of restricted nutrition on puberty in the lamb: pattern of tonic luteinizing hormone ( $\mathrm{LH}$ ) secretion and competency of the LH surge system. Endocrinology 116, 375-381.

Foster, D.L., Michelson, I.H., Ryan, K.D., Coon, G.A., Drongawaski, R.A. \& Holt, J.A. (1978) Ontogey of pulsatile luteinizing hormone and testosterone secretion in maie lambs. Endocrinology 102, 1137-1 146.
Frisch, R.E. (1972) Weight at menarche: similarity for well-nourished and undernourished girls at differing ages, and evidence for historical constancy. Pediatrics 50, 445-450.

Frisch, R.E. \& Revelle, R. (1970) Height and weight at menarche and a hypothesis of critical bodyweights and adolescent events. Science, N.Y. 169, 397-398.

Frisch, R.E. \& Revelle, R. (1971) Height and weight at menarche and a hypothesis of menarche. Arch. Dis. Childh. 46, 695-701.

Glass, A.R. \& Swerdloff, R.S. (1980) Nutritional influences on sexual maturation in the rat. Fedn Proc. Fedn Am. Socs exp. Biol. 39, 2360-2364.

Glass, A.R., Harrison, R. \& Swerdloff, R.S. (1976) Effect of undernutrition and amino acid deficiency on the timing of puberty in rats. Pediatr. Res. 10, 951-955.

Glass, A.R., Anderson, J., Herbert, D. \& Vigersky, R.A. (1984) Relationship between pubertal timing and body size in underfed male rats. Endocrinology 115, 19-24.

Hamilton, G.D. \& Bronson, F.H. (1985) Food restriction and reproductive development in wild house mice. Biol. Reprod. 32, 773-778.

Kulin, H.E., Bwibo, N., Mutie, D. \& Sautner, S.H. (1982) The effect of chronic childhood malnutrition on pubertal growth and development. Am. J. Clin. Nutr. 36, 527-536.

Schanbacher, B.D., D'Occhio, M.J. \& Kinder, J.E. (1982) Initiation of spermatogenesis and testicular growth in oestradiol-17ß-implanted bull calves with pulsatile infusion of luteinizing hormone-releasing hormone. J. Endocr. 93, 183-192.

Received 23 August 1985 